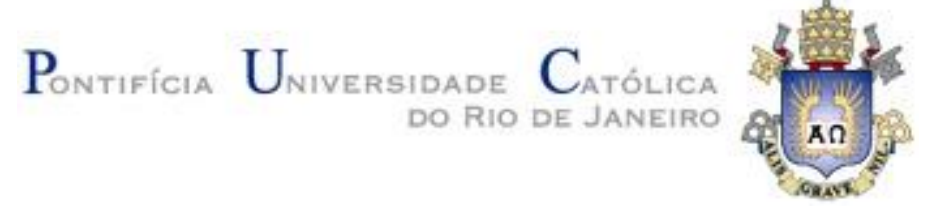

Fernanda Inda de Albuquerque

Determinação de As e Se em Óleo Cru por Espectrometria de Massa com Plasma Indutivamente Acoplado com Célula de Reação Dinâmica (DRC-ICP-MS) e Geração de Hidreto (FI-HG-ICP-MS)

\begin{abstract}
Dissertação de Mestrado
Dissertação apresentada como requisito parcial para obtenção do título de Mestre pelo Programa de Pós-Graduação em Química da PUC-Rio.
\end{abstract}

Orientadora: Prof ${ }^{a}$. Tatiana Dillenburg Saint'Pierre Co-orientadora: Prof ${ }^{a}$. Christiane Béatrice Duyck

Rio de Janeiro

Março de 2011 

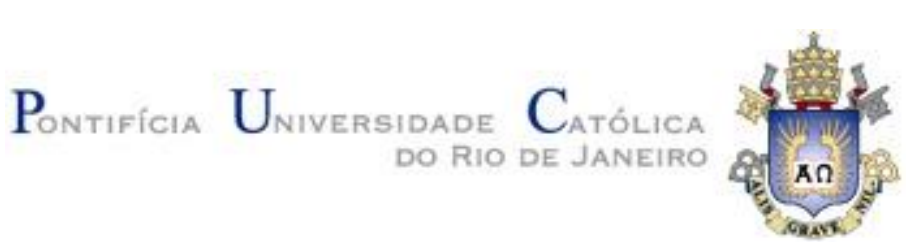

Fernanda Inda de Albuquerque

\title{
Determinação de As e Se em Óleo Cru por Espectrometria de Massa com Plasma Indutivamente Acoplado com Célula de Reação Dinâmica (DRC-ICP-MS) e Geração de Hidreto (FI-HG-ICP-MS)
}

\begin{abstract}
Dissertação apresentada como requisito parcial para obtenção do título de Mestre pelo Programa de Pós-Graduação em Química da PUC-Rio. Aprovada pela Comissão Examinadora abaixo assinada.
\end{abstract}

\author{
Prof'. Tatiana Dillenburg Saint'Pierre \\ Orientadora \\ Departamento de Química - PUC-Rio \\ Prof ${ }^{a}$. Christiane Béatrice Duyck \\ Co-orientadora \\ Departamento de Química - PUC-Rio \\ Prof ${ }^{a}$. Roberta Amorim de Assis \\ UFF \\ Prof. Ricardo Jorgensen Cassella \\ UFF \\ Prof. Anderson de Araújo Rocha \\ UFF \\ Prof. José Eugenio Leal \\ Coordenador Setorial do Centro \\ Técnico Científico - PUC-Rio
}

Rio de Janeiro, 28 de março de 2011 
Todos os direitos reservados. É proibida a reprodução total ou parcial do trabalho sem autorização da universidade, da autora e do orientador.

Fernanda Inda de Albuquerque

Formada em Química Industrial pela Universidade Federal Fluminense em 2008.

Ficha Catalográfica

Albuquerque, Fernanda Inda de
Determinação de As e Se em óleo cru por
espectrometria de massa com plasma indutivamente
acoplado com célula de reação dinâmica (DRC-ICP-MS) e
geração de hidreto (FI-HG-ICP-MS) / Fernanda Inda de
Albuquerque ; orientadores: Tatiana Dillenburg
Saint'Pierre, Christiane B. Duyck. - 2011.
92 f. : il. (color.) ; 30 cm
Dissertação (mestrado)-Pontifícia Universidade
Católica do Rio de Janeiro, Departamento de Química,
2011. $\quad$ Inclui bibliografia Química - Teses. 2. Selênio. 3. Arsênio. 4.
Pontifícia Universidade Católica do Rio de Janeiro.
ICP-MS. 5. Geração de hidreto. 6. DRC. 7. Óleo cru. I.
Saint'Pierre, Tatiana Dillenburg. II. Duyck, Christiane B. III.
Dento de Química. IV. Título.

CDD: 540 


\section{Agradecimentos}

A Deus, por ter me sustentado até aqui.

Às minhas orientadoras, Professoras Tatiana D. Saint'Pierre e Christiane B. Duyck pela orientação e estímulo durante a realização deste trabalho.

Aos meus pais, Celia e Ney, pela oportunidade de estudar, pelos ensinamentos e pelo amor e dedicação que sempre tiveram por mim. Devo tudo a eles.

Ao meu irmão Pedro Henrique, pelos grandes favores prestados, pela amizade e companheirismo.

À minha família, em especial, meus tios Reinaldo e Dayse e meus primos, Fábio e Thaís, por me acolherem em sua casa neste último ano do mestrado e pela amizade cada vez mais sólida que construímos.

Ao meu namorado, Gustavo, que entendeu a minha ausência e por me amparar nos momentos mais difíceis durante esses dois anos.

Aos amigos mais íntimos, em especial, Elaine Marotta, pela companhia nos melhores e piores momentos da minha vida. 
A todos os amigos que fiz aqui na PUC, em especial, Flávia, Eider e "Jeff", pelo auxílio na execução deste trabalho, por me ouvirem diversas vezes e por tornarem este período mais agradável.

Aos professores que participaram da Comissão Examinadora.

Aos amigos do LABSPECTRO, em especial aos técnicos Álvaro e Rafael, por me ajudarem nas análises e no treinamento e por dividirem seus conhecimentos.

Aos funcionários do Departamento de Química da PUC-Rio, em especial à Fátima, pelo companheirismo e ajuda durante esses dois anos.

Ao CNPq pelo auxílio financeiro concedido. 


\section{Resumo}

Albuquerque, Fernanda Inda de; Saint'Pierre, Tatiana Dillenburg. Determinação de As e Se em óleo cru por espectrometria de massa com plasma indutivamente acoplado com célula de reação dinâmica (DRCICP-MS) e geração de hidreto (FI-HG-ICP-MS). Rio de Janeiro, 2011. 92p. Dissertação de Mestrado - Departamento de Química, Pontifícia Universidade Católica do Rio de Janeiro.

Este trabalho teve como proposta o desenvolvimento de uma metodologia para determinação de Se e As em amostras de óleo cru, através da técnica de espectrometria de massas com plasma indutivamente acoplado e célula de reação dinâmica. A vantagem do método proposto está na etapa de preparação das amostras, na qual se emprega a diluição direta em solvente orgânico xileno, eliminando tratamentos prévios, como a digestão. Com isso, a análise fica mais fácil e rápida. Em seguida, foi feita a otimização da célula de reação, empregando o metano como gás de reação. Realizou-se um estudo univariado dos parâmetros de operação da célula, como a vazão do gás de reação e o parâmetro de rejeição q, a fim de reduzir as interferências sobre os isótopos ${ }^{80} \mathrm{Se}$ e ${ }^{75} \mathrm{As}$. Padrões orgânicos de selênio e arsênio diluídos em xileno foram empregados para este estudo e observou-se uma eficiência de redução de interferentes no ${ }^{80} \mathrm{Se}$ de $100 \%$. No caso

do ${ }^{75}$ As, observou-se que o uso da célula não se fez necessário, uma vez que a presença de cloro não foi detectada nas soluções orgânicas. Com os parâmetros da célula apropriados, as condiçõos experimentais foram otimizadas a partir de um estudo univariado. As condições utilizadas foram potência de $1350 \mathrm{~W}$, vazão de argônio de nebulização em $0,40 \mathrm{~L} \mathrm{~min}^{-1} \mathrm{e}$ argônio auxiliar de 0,7 $\mathrm{L} \mathrm{min}^{-1}$. A técnica de adição padrão foi empregada para calibração e os limites de detecção (LODs) instrumentais foram de $0,23\left({ }^{80} \mathrm{Se}\right)$ e $0,018\left({ }^{75} \mathrm{As}\right) \mu \mathrm{g} \mathrm{kg}{ }^{-1}$. A fim de avaliar a exatidão da metodologia aplicada, analisou-se o material certificado NIST 1634c e obtiveram-se boas recuperações, de 97,3\% e 93,5\%, respectivamente, para Se e As. Os intervalos de confiança mostraram que os resultados encontrados para o 
MRC estão dentro da faixa certificada para os dois elementos. A metodologia foi aplicada para análise de nove amostras de petróleo brasileiro. Utilizou-se a técnica de geração de hidretos como forma de comparação com o método proposto. As amostras foram decompostas em bloco de aquecimento e pré-reduzidas com $\mathrm{HCl} 6$ mol $\mathrm{L}^{-1}$. Curvas de calibração externa foram utilizadas na determinação dos isótopos ${ }^{78} \mathrm{Se},{ }^{82} \mathrm{Se}$ e ${ }^{75} \mathrm{As}$, resultando em LODs de aproximadamente $0,04 \mu \mathrm{g} \mathrm{L}{ }^{-1}$ para a determinação de Se total e $0,0022 \mu \mathrm{g} \mathrm{L}^{-1}$ para o As. A exatidão foi avaliada com o NIST 1634c, obtendo boas recuperações de $99,7 \%\left({ }^{78} \mathrm{Se}\right) ; 99,2 \%\left({ }^{82} \mathrm{Se}\right)$ e $100,4 \%\left({ }^{75} \mathrm{As}\right)$. Um tratamento estatístico foi aplicado e mostrou que os resultados obtidos para selênio em todas as nove amostras de óleo foram concordantes pelas duas técnicas empregadas, a um nível de confiança de 95\%. No entanto, somente quatro óleos tiveram resultados de arsênio concordantes pelas duas técnicas. Os outros óleos apresentaram concentrações inferiores para a metodologia de geração de hidretos em relação às concentrações encontradas pela técnica de introdução direta, possivelmente devido a perdas ocorridas durante as etapas de digestão e evaporação. Isto mostra a importância da metodologia desenvolvida para avaliações exatas das concentrações totais de Se e As em petróleos e derivados.

\section{Palavras-chave}

Selênio; Arsênio; ICP-MS; geração de hidreto; DRC; óleo cru. 


\section{Abstract}

Albuquerque, Fernanda Inda de; Saint'Pierre, Tatiana Dillenburg (Advisor). Determination of $\mathrm{As}$ and $\mathrm{Se}$ in crude oil by mass spectrometry with inductively coupled plasma with dynamic reaction cell (DRC-ICP-MS) and hydride generation (FI-HG-ICP-MS). Rio de Janeiro, 2011. 92p. MSc. Dissertation - Departamento de Química, Pontifícia Universidade Católica do Rio de Janeiro.

A methodology was developed for the determination of $\mathrm{Se}$ and $\mathrm{As}$ in samples of crude oil using inductively coupled plasma mass spectrometry with a dynamic reaction cell. The proposed technique of sample preparation showed the advantage of direct dilution in organic solvent, xylene, eliminating previous treatments, such as digestion of samples, and resulting in an easy and fast analytical method. The cell reaction was optimized using methane as the reaction gas. An univariate study was performed with the operating parameters of the cell, the reaction gas flow rate and rejection parameter $\mathrm{q}$, in order to reduce the interferences on isotopes ${ }^{80} \mathrm{Se}$ and ${ }^{75} \mathrm{As}$. Organic standards for arsenic and selenium dissolved in xylene were used for this study and a $100 \%$ reduction efficiency was observed for ${ }^{80} \mathrm{Se}$. In the case of ${ }^{75} \mathrm{As}$, it was observed that the use of the cell was not necessary, since the presence of chlorine was not detected in the organic solutions. With the appropriate experimental conditions for the cell, the experimental conditions were optimized by an univariate study. The conditions used were $1350 \mathrm{~W}$ (RF power), $0.40 \mathrm{~L} \mathrm{~min}^{-1}$ (Ar-nebulizer flow rate) and $0.7 \mathrm{~L} \mathrm{~min}^{-1}$ (Ar-auxiliary flow rate). The standard addition technique was employed for calibration and the instrumental limits of detection (LOD) were $0.23\left({ }^{80} \mathrm{Se}\right)$ and $0.018\left({ }^{75} \mathrm{As}\right) \mathrm{mg} \mathrm{kg}^{-1}$. In order to validate the methodology, the residual fuel oil certified reference material (CRM) NIST 1634c was analyzed and recoveries of $97 \%$ and $94 \%$ were obtained for Se and As, respectively. The confidence intervals showed that the results were within the CRM's range for both elements. The methodology was applied to the analysis of nine samples of 
Brazilian crude oil. A hydride generation methodology was used for comparison with the proposed methodology. The samples were decomposed in a heated block and pre-reduced with $\mathrm{HCl} 6 \mathrm{~mol} \mathrm{~L}^{-1}$. External calibration curves were used to determine ${ }^{78} \mathrm{Se},{ }^{82} \mathrm{Se} \mathrm{e}{ }^{75} \mathrm{As}$, resulting in LODs of approximately $0.04 \mu \mathrm{g} \mathrm{L}^{-1}$ to determine total Se and $0.0022 \mu \mathrm{g} \mathrm{L}^{-1}$ for the As. The accuracy was evaluated also with NIST 1634c, obtaining recoveries of $99.7 \%\left({ }^{78} \mathrm{Se}\right) ; 99.2 \%\left({ }^{82} \mathrm{Se}\right)$ e $100.4 \%$ $\left({ }^{75} \mathrm{As}\right)$. The Snedecor statistical test showed that the results for selenium in all nine oil samples were in agreement by the two techniques at a $95 \%$ confidence level. However, only four oils had concordant results for arsenic by both techniques, the other oils showed lower concentrations for the hydride generation methodology in relation to concentrations found by the direct introduction technique. These results were attributed to losses during the digestion and evaporation steps, and this observation showed the importance of the purposed methodology for accurate assessments of total concentrations of Se and As in crude oil and refined products.

\section{Keywords}

Selenium; Arsenic; ICP-MS; hydride generation; DRC; crude oil. 


\section{Sumário}

1 Introdução 18

2 Revisão Bibliográfica 20

2.1. Petróleo 20

2.1.1. Elementos químicos em petróleo 21

2.1.2. Selênio 22

2.1.2.1 Propriedades físico-químicas 22

2.1.2.2 Produção e aplicação do selênio 23

2.1.2.3 Efeitos biológicos 24

2.1.2.4 Formas de contaminação por Se 24

2.1.2.5 Selênio no petróleo 25

2.1.3. Arsênio 25

2.1.3.1 Propriedades físico-químicas 26

2.1.3.2 Produção e aplicação do arsênio 26

2.1.3.3 Efeitos biológicos $\quad 27$

2.1.3.4 Formas de contaminação 28

2.1.3.5 Arsênio no petróleo 29

2.2. Técnicas analíticas utilizadas na determinação de Se e As 29

2.2.1. Espectrometria de massas com plasma indutivamente acoplado (ICP-MS) 31

2.2.1.1 Interferências em ICP-MS 36

2.2.1.1.1 Interferências não-espectrais 36

2.2.1.1.2 Interferências espectrais 37

2.2.1.2 Célula de reação dinâmica - DRC 38

2.2.2. Sistema de Introdução de amostras 41

2.2.2.1 Introdução de amostra líquida 42

2.2.2.2 Introdução de amostra gasosa por geração de hidretos 43 
3 Objetivos 48

3.1. Objetivo Geral 48

3.2. Objetivos Específicos 48

4 Experimental 49

4.1. Materiais e Métodos 49

4.1.1. Reagentes e Soluções 49

4.1.2. Instrumentação $\quad 50$

4.1.3. Determinação de Se e As por injeção direta com uso da célula de reação (DRC-ICP-MS) 50

4.1.3.1. Otimização dos parâmetros operacionais 52

4.1.3.2. Curvas analíticas 53

4.1.4. Determinação de Se e As por geração de hidretos 54

4.1.4.1. Disgestão das amostras de óleo cru 54

4.1.4.2. Pré-redução dos analitos 55

4.1.4.3. Curvas analíticas $\quad 56$

4.1.4.4. Condições operacionais 56

5 Resultados e discussões $\quad 58$

5.1. Determinação de Se e As por injeção direta com uso da célula de reação (DRC-ICP-MS) 58

5.1.1. Escolha do solvente 58

5.1.2. Otimização dos parâmetros da célula de reação 60

5.1.3. Otimização das condições operacionais do plasma 63

5.1.4. Avaliação da exatidão do método 68

5.1.5. Aplicação analítica 70

5.2. Determinação de Se e As por geração de hidretos 74

5.2.1. Avaliação da exatidão do método 77

5.2.2. Otimização da célula para medição de ${ }^{80}$ Se após a HG 77 
5.3. Comparação das técnicas empregadas neste trabalho

6 Conclusão

83

7 Referências

85

8 Anexo 1

91

9 Anexo II

92 


\section{Lista de Figuras}

Figura 1: contaminação de selênio na cadeia alimentar 25

Figura 2: plasma indutivamente acoplado (ICP) 33

Figura 3: interface que acopla a tocha com o

espectrômetro de massas 34

Figura 4: esquema de um ICP-MS 35

Figura 5: esquema de um DRC-ICP-MS 38

Figura 6: diagrama de estabilidade dos íons na célula de reação $\quad 40$

Figura 7: nebulizador de vidro concêntrico 43

Figura 8: sinal transiente, onde o máximo de concentração do analito está indicado 46

Figura 9: ICP-MS utilizado neste trabalho com o sistema

FIAS acoplado

50

Figura 10: esquema da formação do aerossol pelo

Micronebulizador PFA 51

Figura 11: Ponto de adição de oxigênio 52

Figura 12: bloco de aquecimento/digestor DAB-3 54

Figura 13: Qspl (Quantity solvent plasma loaded) em

função da temperatura

Figura 14: (A)Otimização da vazão do gás de reação

$\left(\mathrm{CH}_{4}\right)$ para o isótopo ${ }^{80} \mathrm{Se}$

(B)Otimização da vazão do gás de reação

$\left(\mathrm{CH}_{4}\right)$ para o isótopo ${ }^{75} \mathrm{As}$

Figura 15: otimização do parâmetro de rejeição Rpq para o isótopo ${ }^{80} \mathrm{Se} \quad 62$

Figura 16: otimização univariada do Ar de nebulização para o Se 63 
Figura 17: otimização univariada da potência para o Se 64

Figura 18: otimização univariada do Ar auxiliar para o Se 65

Figura 19: Gráficos de Pareto gerados na otimização das

condições operacionais para determinação de Se e As

nas amostras diluídas em xileno $\quad 67$

Figura 20: curva analítica do NIST 1634c na determinação de Se 68

Figura 21: curva analítica do NIST 1634c na determinação de As 69

Figura 22: avaliação da vazão do gás de reação para o

óleo B na análise de ${ }^{80} \mathrm{Se}$

Figura 23: gráfico de avaliação de interferentes no isótopo ${ }^{78} \mathrm{Se} \quad 73$

Figura 24: avaliação do Ar de nebulização na análise de ${ }^{82} \mathrm{Se} \quad 74$

Figura 25: avaliação da potência na análise de ${ }^{82} \mathrm{Se} \quad 76$

Figura 26: otimização do gás de reação para a determinação

de ${ }^{80} \mathrm{Se} \quad 78$

Figura 27: avaliação da SBR com a variação da vazão do gás de reação 


\section{Lista de Tabelas}

Tabela 1: análise elementar do óleo cru 20

Tabela 2: ocorrência de selênio no ambiente americano 22

Tabela 3: propriedades físicas do selênio 23

Tabela 4: propriedades físicas do arsênio 26

Tabela 5: trabalhos encontrados na literatura para a

determinação de Se e As $\quad 30$

Tabela 6: trabalhos encontrados na literatura para

análise por introdução direta 31

Tabela 7: potenciais interferências existentes na

determinação de Se por ICP-MS 38

Tabela 8: principais sistemas de introdução de amostras

no ICP-MS

Tabela 9: condições operacionais empregadas na análise

por injeção direta

53

Tabela 10: programa de temperatura do bloco digestor

para a decomposição das amostras e descontaminação

dos frascos 55

Tabela 11: parâmetros operacionais do ICP-MS (ELAN DRC II) 57

Tabela 12: valores mínimo, máximo e ponto central (0)

das variáveis empregadas na otimização multivariada 65

Tabela 13: matriz de planejamento para identificação das

variáveis significativas na determinação de Se e As por

DRC-ICP-MS 66

Tabela 14: LOD e LOQ calculados para os elementos Se e As $\quad 69$ 
Tabela 15: resultados obtidos pela análise do MRC

NIST 1634c (concentrações em $\mu \mathrm{g} \mathrm{kg}^{-1}$ ) para as triplicatas

Tabela 16: valores de sensibilidade e LOD obtidos na

determinação de Se e As nas nove amostras de óleos

71

Tabela 17: valores de sensibilidade e razão sinal/branco para as vazões de $\mathrm{Ar}$ de nebulização estudadas

Tabela 18: valores de sensibilidade e razão sinal/branco

para os valores de potência estudados

Tabela 19: resultados obtidos pela análise do MRC

NIST 1634c (concentrações em $\mu \mathrm{g} \mathrm{L}^{-1}$ )

77

Tabela 20: valores de concentração encontradas na análise

de Se e As em óleo cru

81

Tabela 21: teste de hipótese para comparação entre as duas metodologias na determinação de Se

Tabela 22: teste de hipótese para comparação entre as duas metodologias na determinação de As

82 


\section{Lista de Abreviaturas}

ICP-MS - Epectrometria de Massa com Plasma

Indutivamente Acoplado

DRC - Célula de Reação Dinâmica

HG - Geração de Hidreto

FI-HG-ICP-MS - Geração de Hidreto com Injeção em Fluxo

FIA - Análise por Injeção em Fluxo

DRC-ICP-MS - Epectrometria de Massa com Plasma

Indutivamente Acoplado e com Célula Dinâmica de Reação

RF - Rádiofrequência

NIST - National Institute of Standards and Technologies, USA

SPR - Solução Pré-Redutora

SBR - Razão Sinal/Branco

Qspl - Quantity Solvent Plasma Loaded

Rpq - Parâmetro de Rejeição q

LOD - Limite de Detecção Instrumental

LOQ - Limite de Quantificação

MRC - Material de Referência Certificado 